\title{
Impact Response and Microstructural Evolution of Biomedical Titanium Alloy under Various Temperatures
}

\begin{abstract}
WOEI-SHYAN LEE, TAO-HSING CHEN, and HSIN-HWA HWANG
A compressive split-Hopkinson pressure bar and transmission electron microscope (TEM) are used to investigate the mechanical behavior and microstructural evolution of biomedical $\mathrm{Ti}$ alloy deformed at strain rates ranging from $8 \times 10^{2} \mathrm{~s}^{-1}$ to $8 \times 10^{3} \mathrm{~s}^{-1}$ at temperatures between $25^{\circ} \mathrm{C}$ and $900{ }^{\circ} \mathrm{C}$. In general, the results indicate that the mechanical behavior and microstructural evolution of the alloy are highly sensitive to both the strain rate and the temperature conditions. The flow-stress curves are found to include both a work-hardening region and a work-softening region. The strain-rate-sensitivity parameter, $\beta$, increases with increasing strain and strain rate but decreases with increasing temperature. The activation energy varies inversely with the flow stress and has a low value at high deformation strain rates and low temperatures. Microstructural observations reveal that the strengthening effect evident in the deformed alloy is a result primarily of dislocations and the formation of $\alpha$ phase. The dislocation density increases with increasing strain rate but decreases with increasing temperature. Additionally, the square root of the dislocation density varies linearly with the flow stress. Correlating the mechanical properties of the biomedical $\mathrm{Ti}$ alloy with the TEM observations, it is inferred that the precipitation of $\alpha$ phase dominates the fracture strain. Transmission electron microscope observations reveal that the amount of $\alpha$ phase increases with increasing temperature below the $\beta$-transus temperature. The maximum amount of $\alpha$ phase is formed at a temperature of $700{ }^{\circ} \mathrm{C}$ and results in the minimum fracture strain observed under the current loading conditions.
\end{abstract}

DOI: $10.1007 / \mathrm{s} 11661-008-9514-5$

(C) The Author(s) 2008

\section{INTRODUCTION}

TITANIUM alloys are characterized by a high strength to weight ratio, excellent corrosion resistance, and good formability. Consequently, such alloys are extensively used for applications requiring light-weight, chemically-inert components. In the mid 1980s, $\alpha+\beta$ phase Ti-6Al-4V was commonly regarded as an ideal material for medical implants. ${ }^{[1,2]}$ However, recent research has revealed that Ti-6Al-4V debris contains Group $\mathrm{V}$ chemical elements, which are harmful to human health. ${ }^{[3]}$ Accordingly, researchers have shown increasing interest in the potential of $\beta$-phase $\mathrm{Ti}$ alloy for medical applications. ${ }^{[4,5]}$ In general, this alloy is known to have good biocompatibility characteristics and favorable mechanical properties. However, its dynamic mechanical behavior under the high-strain-rate and temperature conditions experienced during typical manufacturing processes, i.e., forging and machining, are poorly understood. As a result, the precise shape and mechanical properties of manufactured Ti-alloy components are not easily predicted.

In general, strain rate has a crucial effect on the mechanical behavior of deformed materials. Although

WOEI-SHYAN LEE, Distinguished Professor, TAO-HSING CHEN and HSIN-HWA HWANG, Graduate Students, are with the Department of Mechanical Engineering, National Cheng Kung University, Tainan 701, Taiwan R.O.C. Contact e-mail: wslee@mail. ncku.edu.tw

Manuscript submitted October 15, 2007.

Article published online April 5, 2008 the flow stress increases with increasing strain rate in engineering materials, the actual effect of the strain rate is very much dependent on the nature of the tested material. ${ }^{[6-9]}$ Besides the strain rate, the temperature is also known to have a significant effect on the mechanical properties and microstructure of deformed materials. In general, a higher temperature reduces the internal resistance to dislocation movements and results in plastic flow. However, due to the combined effects of work hardening and work softening caused by impact loading and elevated deformation temperatures, respectively, predicting the overall plastic-flow response is problematic.

Intuitively, it seems reasonable to assume that the variations observed in the stress-strain curves of impacted specimens are related to the microstructural evolution of the deformed material. ${ }^{[10]}$ Accordingly, observations of the deformed microstructures of impacted specimens can provide useful insights into the strengthening mechanisms and plastic deformation behavior of materials subjected to deformation under different strain rate and temperature conditions. Dislocation slip is known to have a significant effect on the flow- stress curves of plastically deformed materials. Under high-strain-rate loading conditions, the rapid multiplication of dislocations suppresses the dislocationslip phenomenon and induces a strengthening effect. ${ }^{[11,12]}$ However, under high-temperature deformation conditions, the increased temperature not only increases the annihilation of dislocations but also provides the dislocations with additional energy with which to overcome short-range barriers. As a result, a work-softening effect 
is observed. In other words, the strain rate and temperature exert opposing effects on the mechanical response of engineering materials. Since Ti alloy is a metastable, $\beta$-phase alloy, a strengthening effect is provided by the precipitation of $\alpha$ phase following solution treatment at temperatures lower than the $\beta$-transus temperature $\left(785{ }^{\circ} \mathrm{C}\right) .{ }^{[13]}$ Accordingly, researchers have proposed several thermal treatments designed specifically to control the features and amount of precipitated $\alpha$ phase in order to enhance the mechanical properties of $\mathrm{Ti}$ alloy. ${ }^{[14-16]}$ In general, the mechanical response of Ti-alloy components is significantly dependent on both the strain rate and the temperature conditions encountered during their manufacture or subsequent service lives. Consequently, it is essential to systematically examine the correlation between the mechanical properties of Ti alloy and its microstructural evolution over a range of strain rate and temperature loading conditions.

Accordingly, this study employs a compressive splitHopkinson pressure bar (SHPB) to investigate the mechanical response of $\mathrm{Ti}$ alloy (i.e., the yield stress, the maximum stress, the fracture strain, and the rate of work hardening) under strain rates between $8 \times 10^{2} \mathrm{~s}^{-1}$ and $8 \times 10^{3} \mathrm{~s}^{-1}$ and temperatures ranging from $25^{\circ} \mathrm{C}$ to $900{ }^{\circ} \mathrm{C}$. The microstructural evolution of the deformed specimens is observed via TEM, with particular attention paid to the effects of the strain rate and temperature on the formation and slip of microstructural dislocations and the extent of $\alpha$-phase precipitation. Finally, the correlation between the microstructural evolution characteristics and the macromechanical response of the deformed specimens is systematically analyzed and discussed.

\section{EXPERIMENTS}

The Ti alloy tested in this study was solution treated at a temperature of $735^{\circ} \mathrm{C}$ for 0.5 to 1 hour and then aged at $425^{\circ} \mathrm{C}$ to $500{ }^{\circ} \mathrm{C}$ for 17 hours. The chemical composition (wt pct) of the alloy was as follows: $1.1 \mathrm{pct}$ Mo, 5.2 pet Zr, 2.9 pet Al, 0.35 pct Fe, 0.05 pct N, 0.20 pet $\mathrm{O}, 0.02$ pet $\mathrm{H}$, and a balance of Ti. Rods with a diameter of $25 \mathrm{~mm}$ and a length of $170 \mathrm{~mm}$ were formed in a drawing process, and cylindrical specimens with a diameter and height of $7 \mathrm{~mm}$ were then machined, using an electrodischarge machine. The specimen surfaces were carefully ground to ensure a close contact between the specimen and the pressure bars of the SHPB apparatus during the high-strain-rate tests.

The Ti-alloy specimens were compression tested at strain rates of $8 \times 10^{2} \mathrm{~s}^{-1}, 3 \times 10^{3} \mathrm{~s}^{-1}$, and $8 \times 10^{3} \mathrm{~s}^{-1}$ and temperatures of $25^{\circ} \mathrm{C}, 300{ }^{\circ} \mathrm{C}, 500{ }^{\circ} \mathrm{C}, 700{ }^{\circ} \mathrm{C}$, and $900{ }^{\circ} \mathrm{C}$, respectively. Figure 1 presents an illustration of the experimental setup and the measurement apparatus. The striker, incident, and transmitter bars of the SHPB apparatus were fabricated of DC 53 high-strength tool steel and had a diameter of $12.7 \mathrm{~mm}$. The SHPB apparatus and experimental procedures are well documented by Lindholm, ${ }^{[1]}$ and, hence, the following discussions present no more than a brief outline of the experimental process.

In the high-strain-rate tests, the striker bar was fired by a gas gun such that it impacted the end of the incident bar. The resulting compressive wave propagated along the incident bar until it reached the specimen interface, at which point it separated into two parts, i.e., a reflected wave and a transmitted wave. The magnitudes of the reflected and transmitted waves, i.e., $\varepsilon_{r}$ and $\varepsilon_{t}$, respectively, were detected by electroresistance strain gages mounted on the incident and transmitter bars. According to one-dimensional elastic-wave propagation theory, the compression strain, $\varepsilon$, strain rate, $\dot{\varepsilon}$, and stress, $\sigma$, are given by the following equations:

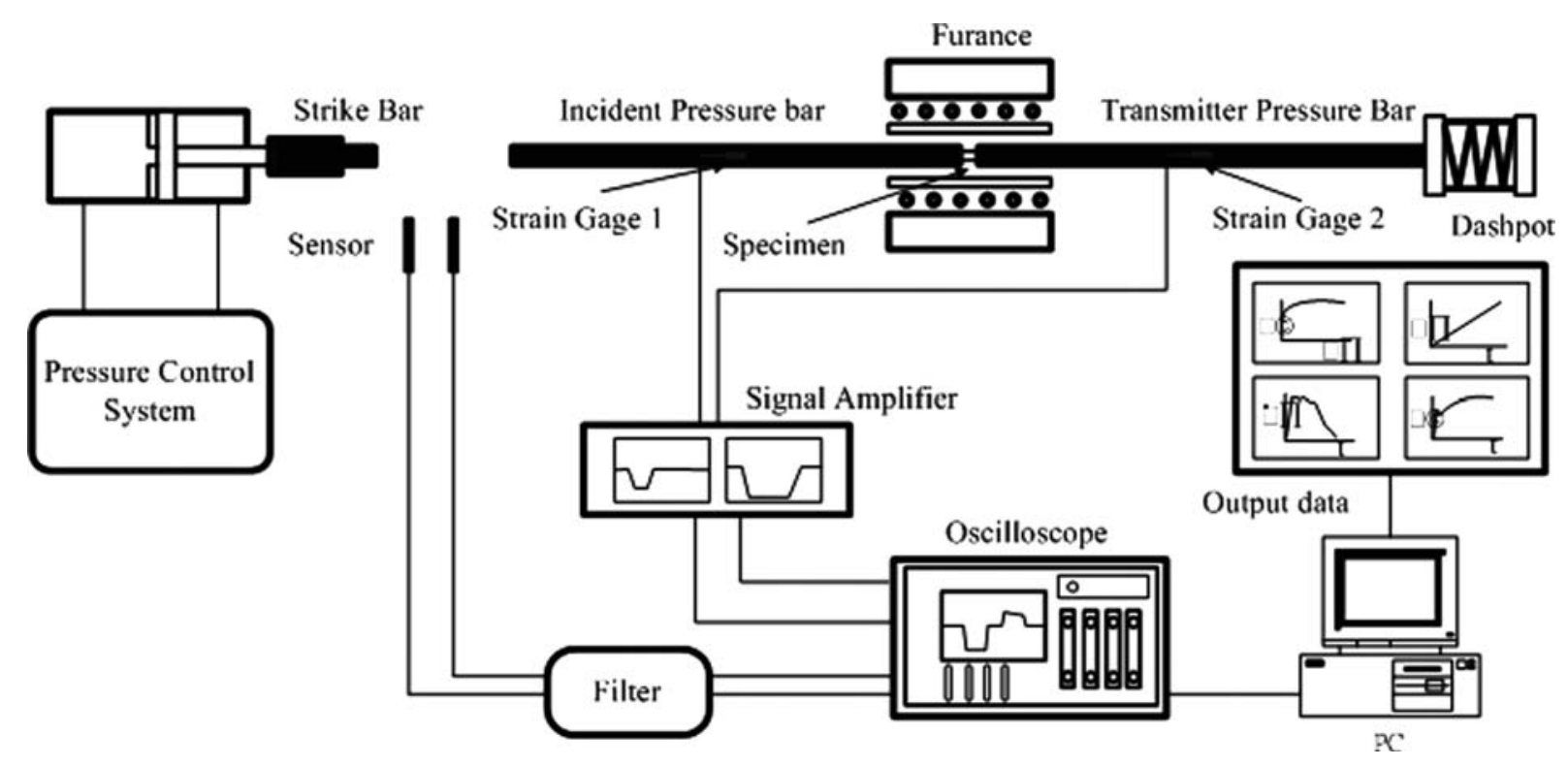

Fig. 1-Schematic illustration of a compressive split-Hopkinson bar apparatus. 


$$
\begin{gathered}
\varepsilon=\frac{-2 C_{0}}{L} \int_{0}^{t} \varepsilon_{r} d t \\
\dot{\varepsilon}=\frac{-2 C_{0}}{L} \varepsilon_{r} \\
\sigma=\frac{E A}{A_{s}} \varepsilon_{t}
\end{gathered}
$$

where $C_{0}$ is the longitudinal-wave velocity in the splitHopkinson bar, $L$ is the effective gage length of the specimen, $E$ is the Young's modulus of the split bar, and $A$ and $A_{s}$ are the cross-sectional areas of the split bar and the specimen, respectively.

For the compression tests performed at elevated temperatures of $300{ }^{\circ} \mathrm{C}, 500{ }^{\circ} \mathrm{C}, 700{ }^{\circ} \mathrm{C}$, and $900{ }^{\circ} \mathrm{C}$, respectively, the specimens were enclosed in a clamshell radiantheating furnace with an internal diameter of $25 \mathrm{~mm}$ and a heating element with a length of $300 \mathrm{~mm}$. The specimen temperature was monitored using a K-type (chromelalumel) thermocouple positioned in contact with the specimen surface. Prior to testing, the specimen and the two ends of the pressure bars holding the specimen were maintained at the designated testing temperature for a duration of approximately 10 minutes to ensure a uniform temperature distribution at the specimen/pressure bar interface. The resulting temperature gradient induced along the lengths of the two pressure bars affects both the elastic modulus of the bars and the propagation velocity of the pressure pulse. Accordingly, it is necessary to modify the original equations for the strain, strain rate, and stress given in Eqs. [1] through [3]. (Note that the necessary modifications are summarized in previous studies by Chiddister and Malvern ${ }^{[18]}$ and the current authors ${ }^{[19]}$ and are therefore not described here.)

Following the high-strain-rate tests, the microstructures of the deformed specimens were observed via TEM in order to investigate the respective effects of the strain rate and temperature on the formation of dislocations and the precipitation of $\alpha$ phase. The thin foils required for the TEM observations were prepared by cutting slices of $0.7-\mathrm{mm}$ thickness from the center of the deformed specimens in a direction perpendicular to the compression axis using a diamond-bladed cutting machine. The slices were ground with 600-grit paper to a thickness of $0.2 \mathrm{~mm}$, and discs with a diameter of $3 \mathrm{~mm}$ were then removed using a spark cutter. The discs were electropolished in a twin-jet polishing machine, using a solution of Methanol (500 mL), I-Butanol (300 mL), and Perchloric acid $(50 \mathrm{~mL})$ at $25^{\circ} \mathrm{C}$ and a $20 \mathrm{~V}$ DC voltage. Finally, the electropolished disks were ion milled by argon in a Gatan PIPS-691 (Gatan, Inc. 5794 W. Las Positas Blvd. Pleasanton, CA) Ion-Miller with an accelerating voltage of $4.5 \mathrm{keV}$ and a beam glancing angle of $4 \mathrm{deg}$. The specimens were then examined using a JEOL* TEM-3010 analytical

*JEOL is a trademark of Japan Electron Optics Ltd., Tokyo.

scanning TEM with an operating voltage of $300 \mathrm{kV}$.

\section{RESULTS AND DISCUSSION}

\section{A. Stress-Strain Curves}

Figures 2(a) through (c) present the stress-strain curves of Ti-alloy specimens deformed at strain rates of $8 \times 10^{2} \mathrm{~s}^{-1}, 3 \times 10^{3} \mathrm{~s}^{-1}$, and $8 \times 10^{3} \mathrm{~s}^{-1}$, respectively, at temperatures between $25{ }^{\circ} \mathrm{C}$ and $900{ }^{\circ} \mathrm{C}$. In general, it is observed that the flow stress increases with increasing strain rate but decreases with increasing temperature. It can also be seen that for a constant strain rate, the flow stress increases with increasing strain initially but then reduces as the strain is increased further. Table I summarizes the yield stress, fracture strain, and maximum stress for each of the current specimens. The results show that the yield stress and the maximum stress both increase with increasing strain rate but decrease with increasing temperature. At the lowest strain rate of $8 \times 10^{2} \mathrm{~s}^{-1}$, the specimen fractures only at a deformation temperature of $25^{\circ} \mathrm{C}$. However, when the strain rate is increased to $8 \times 10^{3} \mathrm{~s}^{-1}$, all the specimens fracture, irrespective of the temperature conditions. Hence, the results show that Ti alloy fractures more readily at higher strain rates or lower temperatures. Table I also shows that for a constant temperature, the fracture strain increases with increasing strain rate, which suggests that the fracture toughness of the alloy is enhanced at higher strain rates. Finally, it is observed that for a given strain rate, the fracture strain reduces with increasing temperature at temperatures lower than $700{ }^{\circ} \mathrm{C}$ but increases significantly at a deformation temperature of $900{ }^{\circ} \mathrm{C}$. This tendency implies that an increasing deformation temperature is accompanied by a significant change in the microstructure of the $\mathrm{Ti}$ alloy, particularly at temperatures between $700{ }^{\circ} \mathrm{C}$ and $900{ }^{\circ} \mathrm{C}$.

Figure 2(d) compares the experimental stress-strain data obtained for the current $\mathrm{Ti}$ alloy under various temperature and strain rate conditions with those presented in the literature for $\alpha$-phase $\mathrm{Ti}$ alloy and Ti-6Al-4V alloy tested under broadly equivalent conditions. ${ }^{[20-22]}$ It can be seen that the flow stress of the current biomedical $\mathrm{Ti}$ alloy is greater than that of the $\alpha$-phase Ti alloy under both temperature and strain-rate conditions and is higher than that of the Ti-6Al-4V alloy tested at $725^{\circ} \mathrm{C}$ and $3.7 \times 10^{3} \mathrm{~s}^{-1}$. However, the flow stress of the Ti-6Al-4V alloy deformed at $25^{\circ} \mathrm{C}$ and $3.4 \times 10^{3} \mathrm{~s}^{-1}$ is slightly higher than that of the current $\mathrm{Ti}$ alloy under similar loading conditions (i.e., a temperature of $25^{\circ} \mathrm{C}$ and a strain rate of $3 \times 10^{3} \mathrm{~s}^{-1}$ ).

The stress-strain curves in Figure 2 show signs of both work hardening and work softening as the deformation strain is progressively increased. Figure 3 plots the work- hardening rate, i.e., the slope of the stress-strain curves $(\partial \sigma / \partial \varepsilon)$, against the deformation temperature as a function of the strain rate at true strains of 0.1 and 0.2 . For an engineering material, the work-hardening rate represents the net result of the competing effects of work hardening (induced by the strain and strain rate) and work softening (induced by the testing temperature and the deformation-heating effect). Overall, a negative rate of work hardening indicates that the deformation is dominated by a work-softening mechanism. Figure 3 


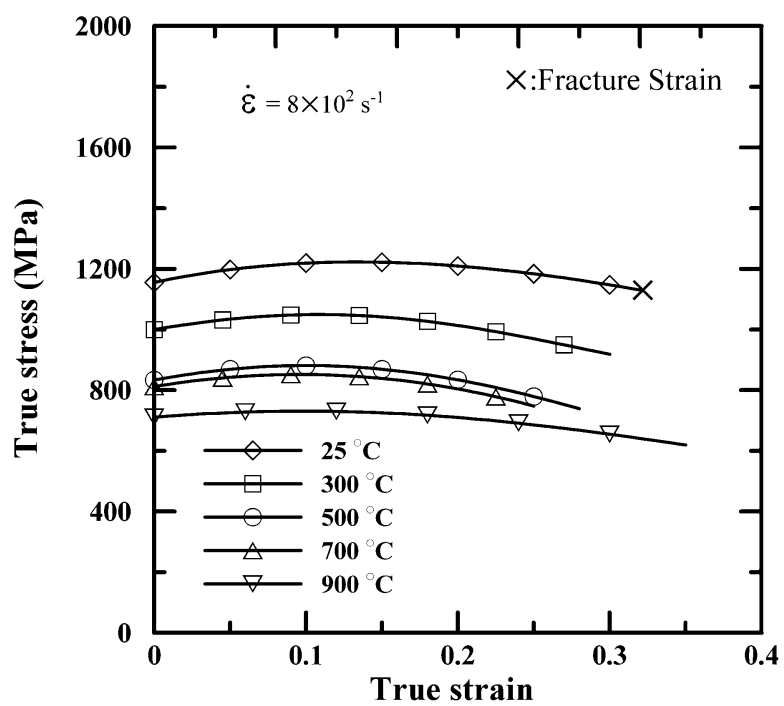

(a)

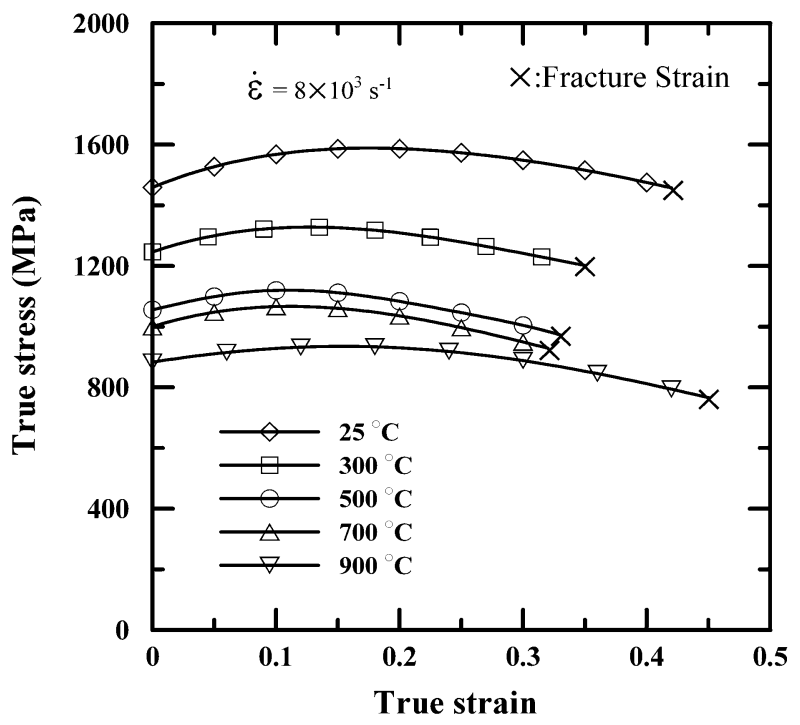

(c)

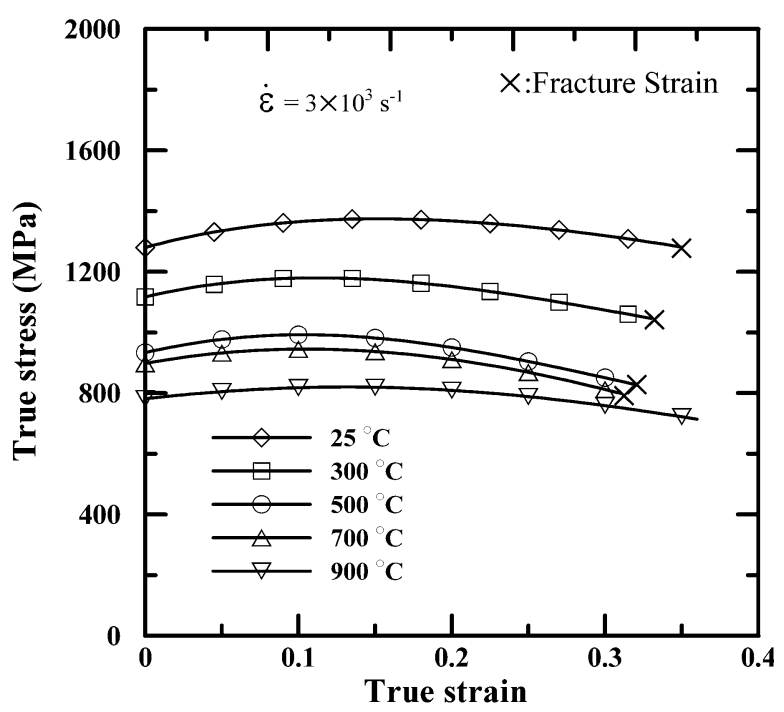

(b)

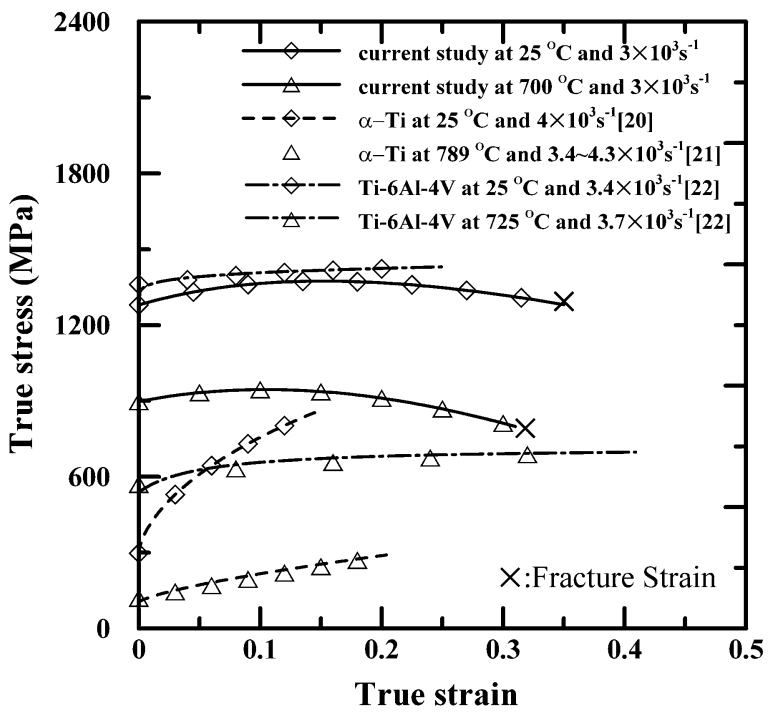

(d)

Fig. 2 - True stress-strain curves of Ti alloy deformed at various temperatures under strain rates of (a) $8 \times 10^{2} \mathrm{~s}^{-1}$, (b) $3 \times 10^{3} \mathrm{~s}^{-1}$, and $(c)$ $8 \times 10^{3} \mathrm{~s}^{-1}$; and $(d)$ comparison of current stress-strain results and those presented in the literature for $\alpha$-phase Ti alloy and Ti-6Al-4V alloy under equivalent temperature and strain-rate conditions.

shows that for the current Ti alloy, the work-hardening rate increases with increasing strain rate at a constant temperature, which indicates a greater resistance to plastic deformation under higher strain-rate loading conditions. However, the temperature rise caused by the deformation heat produced under high-strain-rate loading reduces the work-hardening rate as the true strain increases under constant temperature conditions. For a constant strain rate, the work- hardening rate decreases with increasing temperature at temperatures lower than $700{ }^{\circ} \mathrm{C}$ but increases significantly (particularly at a higher true strain) when the deformation temperature is increased to $900{ }^{\circ} \mathrm{C}$. Generally speaking, the greater thermal energy associated with a higher deformation temperature enhances the ability of dislocations to overcome short-range barriers. Therefore, the work-hardening rate decreases with increasing temperature at temperatures lower than $700{ }^{\circ} \mathrm{C}$. However, at temperatures higher than the $\beta$-transus temperature of the current $\mathrm{Ti}$ alloy, i.e., $785^{\circ} \mathrm{C}$, the microstructural transition from $\alpha+\beta$ phase to pure $\beta$ phase results in an increased work-hardening rate.

\section{B. Strain Rate Effect and Activation Energy}

The stress-strain curves presented in Figure 2 indicate that the strain rate has a significant effect on the flow stress of Ti alloy. In order to analyze the strain-rate effect on the mechanical behavior of the deformed alloy under different loading conditions, Figure 4(a) illustrates the relationship between the flow stress and the strain rate as a function of the temperature at true 
Table I. Mechanical Properties and Fracture States of Ti Alloy Deformed at Strain Rates of $8 \times 10^{2} \mathrm{~s}^{-1}, 3 \times 10^{3} \mathrm{~s}^{-1}$, and $8 \times 10^{3} \mathrm{~s}^{-1}$ at Temperatures Ranging from $25^{\circ} \mathrm{C}$ to $900{ }^{\circ} \mathrm{C}$

\begin{tabular}{|c|c|c|c|c|c|c|}
\hline Temperature $\left({ }^{\circ} \mathrm{C}\right)$ & $\begin{array}{c}\text { Strain } \\
\text { Rate }\left(s^{-1}\right)\end{array}$ & $\begin{array}{c}\text { Yield } \\
\text { Stress (MPa) }\end{array}$ & $\begin{array}{c}\text { Maximum } \\
\text { Stress (MPa) }\end{array}$ & $\begin{array}{c}\text { Fracture } \\
\text { Stress (MPa) }\end{array}$ & $\begin{array}{l}\text { Fracture } \\
\text { Strain }\end{array}$ & $\begin{array}{c}\text { Fracture } \\
\text { State }\end{array}$ \\
\hline \multirow[t]{3}{*}{25} & $8.0 \times 10^{2}$ & 1155 & 1223 & 1130 & 0.32 & 0 \\
\hline & $3.0 \times 10^{3}$ & 1280 & 1374 & 1281 & 0.35 & $\oplus$ \\
\hline & $8.0 \times 10^{3}$ & 1459 & 1588 & 1457 & 0.42 & $\oplus$ \\
\hline \multirow[t]{3}{*}{300} & $8.0 \times 10^{2}$ & 1000 & 1050 & - & - & $\bigcirc$ \\
\hline & $3.0 \times 10^{3}$ & 1117 & 1180 & 1047 & 0.33 & $\oplus$ \\
\hline & $8.0 \times 10^{3}$ & 1246 & 1328 & 1202 & 0.35 & $\oplus$ \\
\hline \multirow[t]{3}{*}{500} & $8.0 \times 10^{2}$ & 833 & 881 & - & - & $\bigcirc$ \\
\hline & $3.0 \times 10^{3}$ & 934 & 993 & 828 & 0.32 & 0 \\
\hline & $8.0 \times 10^{3}$ & 1055 & 1121 & 973 & 0.33 & $\oplus$ \\
\hline \multirow[t]{3}{*}{700} & $8.0 \times 10^{2}$ & 811 & 852 & - & - & $\bigcirc$ \\
\hline & $3.0 \times 10^{3}$ & 898 & 945 & 799 & 0.30 & 0 \\
\hline & $8.0 \times 10^{3}$ & 1000 & 1067 & 914 & 0.32 & $\oplus$ \\
\hline \multirow[t]{3}{*}{900} & $8.0 \times 10^{2}$ & 711 & 731 & - & - & $\bigcirc$ \\
\hline & $3.0 \times 10^{3}$ & 781 & 820 & - & - & 0 \\
\hline & $8.0 \times 10^{3}$ & 883 & 935 & 766 & 0.45 & () \\
\hline
\end{tabular}

○: safe, 0 : single shear band, $\oplus$ : single shear band with crack, and $\odot$ : multiple shear bands with crack.

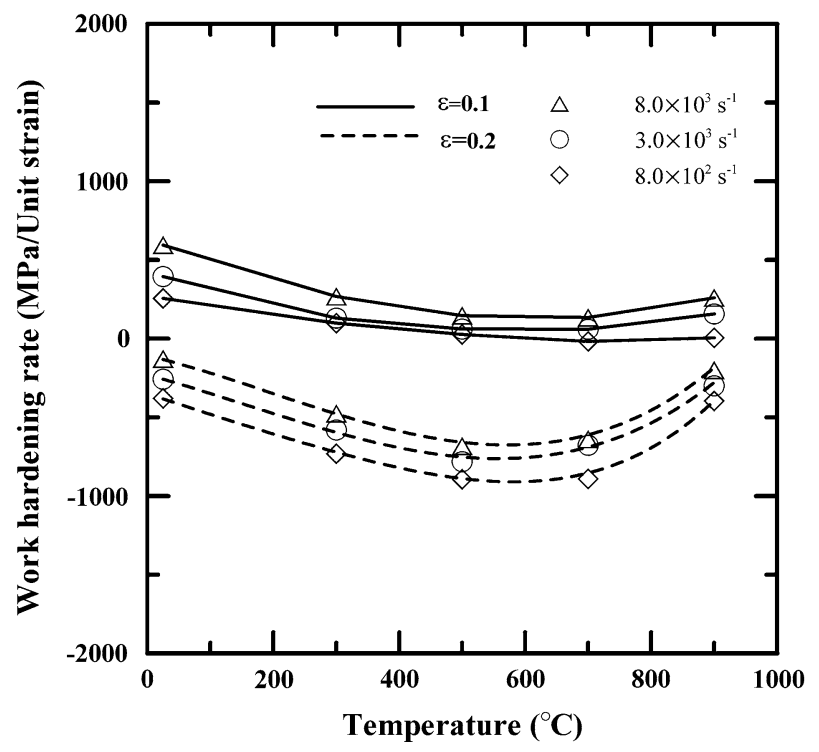

Fig. 3-Variation of work-hardening rate with temperature as function of strain rate at true strains of $(a) 0.1$ and $(b) 0.2$.

strains of 0.1 and 0.2 , respectively. In general, it is apparent that the flow stress increases with increasing strain rate at both values of the true strain. Furthermore, for a given temperature, the flow stress increases more significantly at higher strain rates (i.e., $3 \times 10^{3}$ and $8 \times 10^{3} \mathrm{~s}^{-1}$ ), while for a given strain rate, the stress increases more gradually at higher temperatures.

The literature contains many experimental investigations into the mechanical response of engineering materials subjected to dynamic loading. The results typically reveal that a significant increase in flow stress occurs at strain rates higher than $10^{3} \mathrm{~s}^{-1}$. This phenomenon is thought to indicate a change from a thermally activated control of the dislocation movements at low strain rates to a viscous-drag control mechanism at higher strain rates. ${ }^{[23]}$ However, in their study of copper alloy, Follansbee and Kocks ${ }^{[24]}$ suggested that the increased flow stress at strain rates higher than $10^{3} \mathrm{~s}^{-1}$ was caused, not by a transformation of the deformation mechanism from thermally activated flow to viscous drag, but by an enhanced rate of dislocation generation. The same argument was also advanced by Lee et al. ${ }^{[25]}$ and Zerilli et al. ${ }^{[26]}$ in their studies of $304 \mathrm{~L}$ stainless steel and oxygen-free high conductivity (OFHC) copper, respectively.

The strain-rate effect can be quantified via the strainrate-sensitivity parameter, $\beta$, defined by the following equation: ${ }^{[27]}$

$$
\beta=\left(\sigma_{2}-\sigma_{1}\right) / \ln \left(\dot{\varepsilon}_{2} / \dot{\varepsilon}_{1}\right)
$$

where the compressive stresses $\sigma_{1}$ and $\sigma_{2}$ are obtained from tests conducted at average strain rates of $\dot{\varepsilon}_{2}$ and $\dot{\varepsilon}_{1}$, respectively, and are calculated at the same value of compressive plastic strain. Figure 4(b) illustrates the variation of the strain-rate sensitivity of the current $\mathrm{Ti}$ alloy with the temperature as a function of the strain rate at true strains of 0.1 and 0.2 , respectively. It is observed that the strain-rate sensitivity increases with increasing strain and strain rate but decreases with increasing temperature. Furthermore, at lower strain rates $\left(8 \times 10^{2}\right.$ to $3 \times 10^{3} \mathrm{~s}^{-1}$ ), an approximately linear relationship is found between the strain-rate sensitivity and the temperature. However, at higher strain rates $\left(3 \times 10^{3}\right.$ to $\left.8 \times 10^{3} \mathrm{~s}^{-1}\right)$, the Ti alloy is more strain-rate sensitive at lower temperatures for both values of the true strain.

Assuming that the plastic deformation of the Ti alloy is a thermally activated process, the strain rate can be expressed in the form of the following Arrhenius equation: ${ }^{[28]}$

$$
\dot{\varepsilon}=\dot{\varepsilon}_{0} \exp \left(\frac{-\Delta G^{*}}{\mathrm{k} T}\right)
$$

where $\dot{\varepsilon}_{0}$ is the frequency factor, $\Delta G^{*}$ is the activation energy required to induce plastic flow, $\mathrm{k}$ is the 


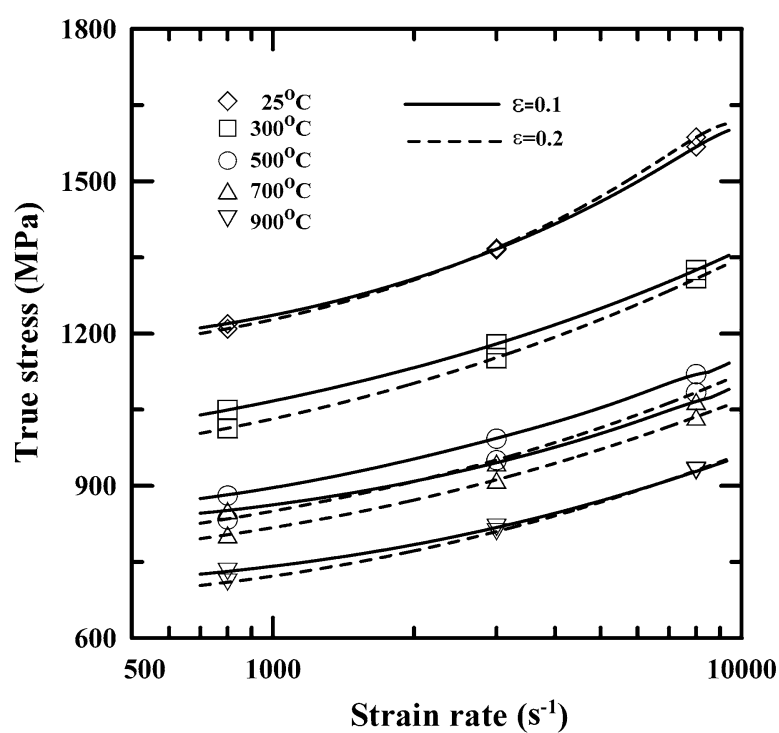

(a)

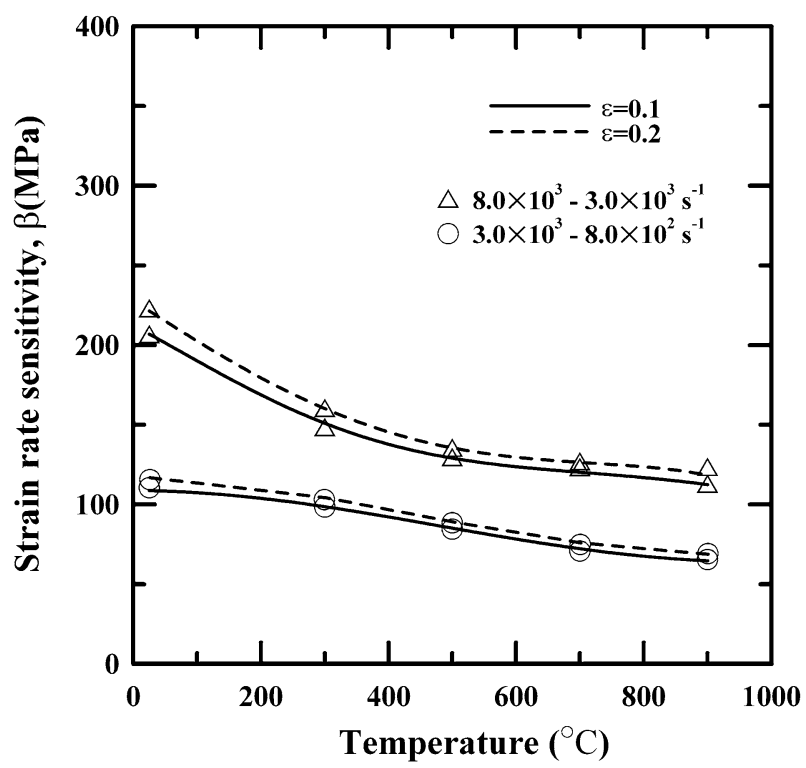

(b)

Fig. $4-(a)$ Variation of flow stress with strain rate as function of temperature at true strains of 0.1 and 0.2 , and $(b)$ variation of strain-rate sensitivity as function of strain rate at true strains of 0.1 and 0.2 .

Boltzmann constant, and $T$ is the absolute experimental temperature. The activation energy associated with the dynamic deformation of the current Ti alloy is given by the following equation: ${ }^{[29,30]}$

$$
\Delta G^{*}=-T v^{*}\left(\frac{\partial \sigma}{\partial T}\right)_{\dot{\varepsilon}, \varepsilon}
$$

where $v^{*}$ is the activation volume and can be obtained from the following equation: ${ }^{[31]}$

$$
v^{*}=\mathrm{k} T\left(\frac{\partial \ln \dot{\varepsilon}}{\partial \sigma}\right)_{T}
$$

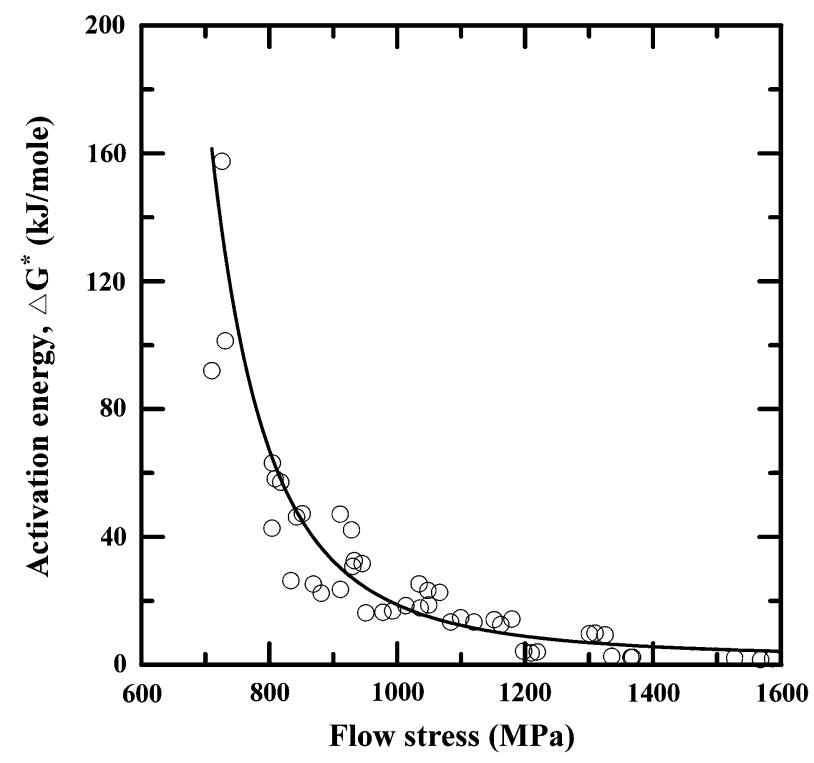

Fig. 5-Variation of activation energy with flow stress.

For the current Ti alloy, sufficient activation energy to trigger the plastic-flow process is obtained at particular combinations of the current strain, strain rate, and temperature conditions. Figure 2 has shown that the flow stress varies as a function of the strain, strain rate, and temperature. Therefore, a correlation can be obtained between the activation energy and the flow stress under equivalent loading conditions, as shown in Figure 5. The results indicate that the flow stress is inversely related to the activation energy. In other words, at activation energies lower than $20 \mathrm{~kJ} / \mathrm{mole}$, the flow stress increases significantly as the activation energy decreases. In general, the role of the activation energy is to assist dislocations in overcoming short-range barriers to movement. In the current case, moving a dislocation requires more stress during plastic deformation, particularly under high-strain-rate and low-temperature loading conditions because $\mathrm{Ti}$ alloy is known to have a low activation energy. ${ }^{[32]}$

\section{Temperature Effect}

The stress-strain curves presented in Figure 2 have shown that the plastic flow is affected not only by the strain rate but also by the temperature. The temperature effect is shown more clearly in Figure 6(a), which plots the variation of the true stress with the temperature as a function of the strain rate. It can be seen that the flow stress drops rapidly as the temperature is increased from $25^{\circ} \mathrm{C}$ to $500{ }^{\circ} \mathrm{C}$, reduces more slowly as the temperature is increased to $700{ }^{\circ} \mathrm{C}$, and then falls abruptly as the temperature is further increased to $900{ }^{\circ} \mathrm{C}$. The variation in flow stress with increasing temperature is the result of microstructural changes, i.e., changes in the grain size, the number of dislocations, the volume and composition of phase, and so forth. In the current Ti alloy, the softening resistance observed at temperatures between $500{ }^{\circ} \mathrm{C}$ and $700{ }^{\circ} \mathrm{C}$ is thought to be the result of a strengthening effect 


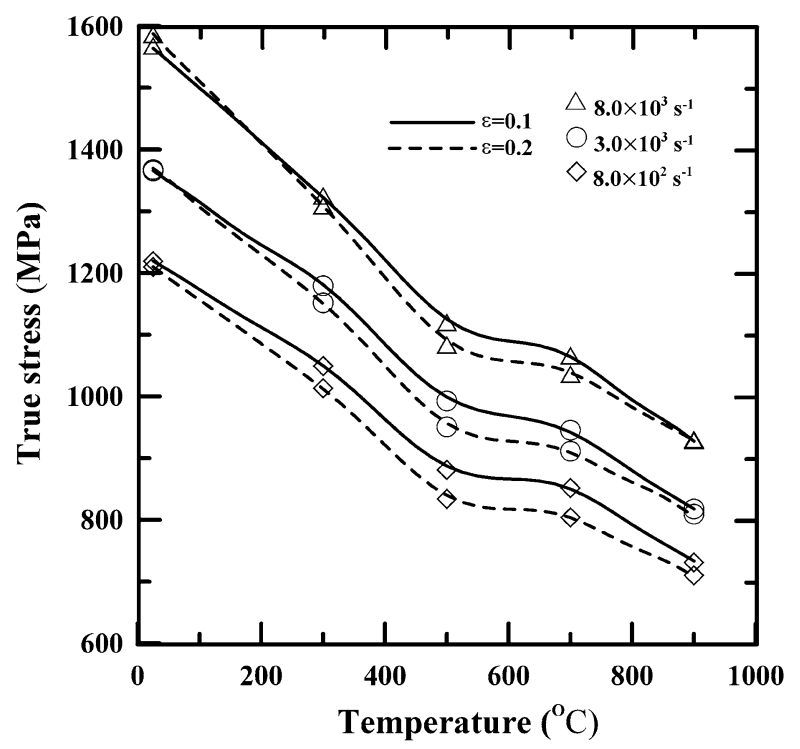

(a)

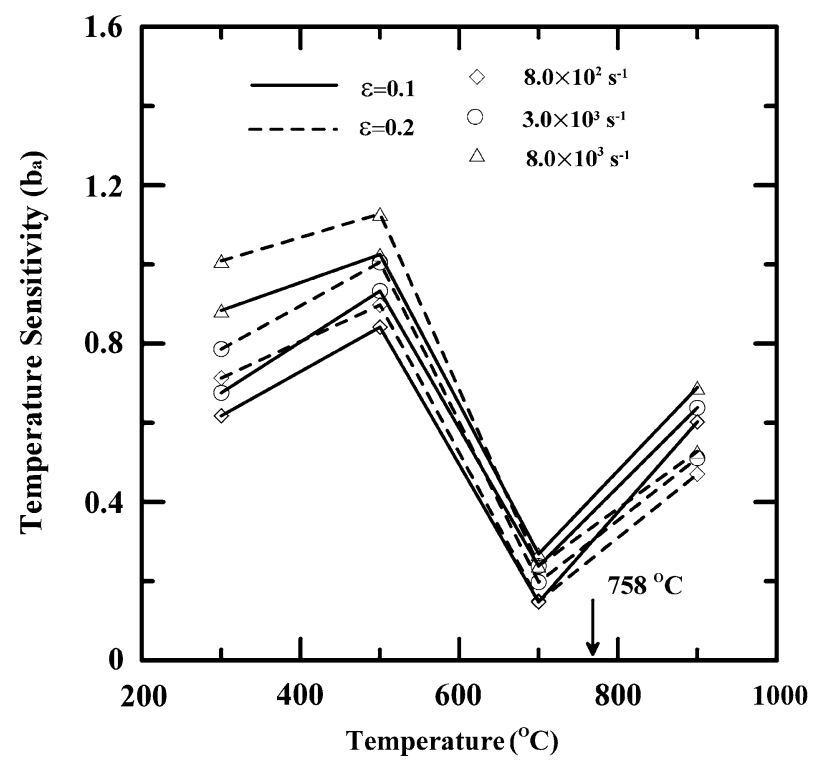

(b)

Fig. 6-Variation of (a) flow stress and (b) temperature sensitivity with temperature as function of strain rate at true strains of 0.1 and 0.2 .

prompted by the formation of $\alpha$ phase as the temperature is increased at temperatures lower than the $\beta$-transus temperature $\left(785^{\circ} \mathrm{C}\right)$. The temperature effect can be quantified via a temperature-sensitivity parameter, $b_{a}$, defined as $\left|\left(\sigma_{2}-\sigma_{1}\right) /\left(T_{2}-T_{1}\right)\right| \cdot{ }^{[33,34]}$ Figure 6(b) shows the correlation between the temperature sensitivity of the Ti alloy and the temperature as a function of the strain and strain rate. It can be seen that the highest temperature sensitivity occurs at $500{ }^{\circ} \mathrm{C}$, while the lowest occurs at $700{ }^{\circ} \mathrm{C}$. It is also apparent that for a constant temperature, the temperature sensitivity increases with increasing strain rate. Thus, it can be inferred that the strain-rateinduced strengthening effect is restrained by the temperature effect. This restraining effect is particularly pronounced at higher strain rates at temperatures of
$300{ }^{\circ} \mathrm{C}$ and $500{ }^{\circ} \mathrm{C}$, respectively. Comparing the temperature sensitivity at true strains of 0.1 and 0.2 , respectively, for a fixed strain rate, it can be seen that the temperaturesensitivity parameter has a higher value at a true strain of 0.2 than at 0.1 for temperatures of $300{ }^{\circ} \mathrm{C}$ and $500{ }^{\circ} \mathrm{C}$. However, at a higher temperature of $700{ }^{\circ} \mathrm{C}$, the temperature-sensitivity parameter has an approximately equal value at true strains of 0.1 and 0.2 , respectively. Finally, at the highest temperature of $900{ }^{\circ} \mathrm{C}$, the temperaturesensitivity parameter has a lower value at a strain of 0.2 than at 0.1 . These results reveal that the temperature effect is more pronounced in specimens subjected to large deformations at low temperatures.

\section{Microstructural Observations}

In the high-strain-rate tests performed in this study, the same heating rate and holding time were applied in every case, i.e., a heating rate of $2 / 3^{\circ} \mathrm{C} / \mathrm{s}$ until the specified testing temperature was attained and a holding time of 15 minutes. Figure 7 shows the initial undeformed microstructures of Ti-alloy specimens heated to each of the current testing temperatures. The grain sizes of the undeformed, heated specimens were measured using a linear intercept method and were found to be 36 , $39,44,47$, and $51 \mu \mathrm{m}$ in the specimens heated to temperatures of $25{ }^{\circ} \mathrm{C}, 300{ }^{\circ} \mathrm{C}, 500{ }^{\circ} \mathrm{C}, 700{ }^{\circ} \mathrm{C}$, and $900{ }^{\circ} \mathrm{C}$, respectively. The macromechanical behavior of the deformed Ti-alloy specimens is closely related to the microstructural changes induced by the applied strain rate and temperature-loading conditions. Figures 8 and 9 present diffraction patterns and TEM micrographs of the $\mathrm{Ti}$ alloy deformed at a true strain of 0.2 under various strain-rate/temperature conditions. The diffraction patterns in Figures 8(a) and (b) reveal the presence of elongated $\alpha$ phase within the $\beta$ matrix of the Ti alloy deformed at $25^{\circ} \mathrm{C}$. The micrographs presented in Figures 8(c) through (f) and Figures 9(a) through (f) reveal that the dislocation density increases with increasing strain rate but decreases with increasing temperature. Furthermore, it can be seen that the amount of $\alpha$ phase increases with increasing temperature at temperatures lower than $700{ }^{\circ} \mathrm{C}$. Observing the dislocation structures, it is found that the dislocation cells are large and have thin walls composed of tangled dislocations in the specimen deformed at a strain rate of $8 \times 10^{2} \mathrm{~s}^{-1}$ and a temperature of $25^{\circ} \mathrm{C}$ (Figure 8(c)). However, at the same deformation temperature, when the strain rate is increased to $8 \times 10^{3} \mathrm{~s}^{-1}$, the dislocation cell size reduces, and the cell walls become thicker (Figure 8(d)). Under this higher strain rate condition, the dislocation density increases, and the greater number of dislocations tangled at the cell walls suppresses dislocation movement. In other words, as the number of tangled dislocations within the cell wall increases, the force required for the dislocations to overcome the barriers formed by these tangled dislocations also increases. Correlating the stress-strain curves in Figure 2 with the increased dislocation density observed at higher strain rates in Figure 8(d), it can be inferred that the flow stress increases as a result of an increasing dislocation density. Although previous research ${ }^{[20]}$ reported the presence of 

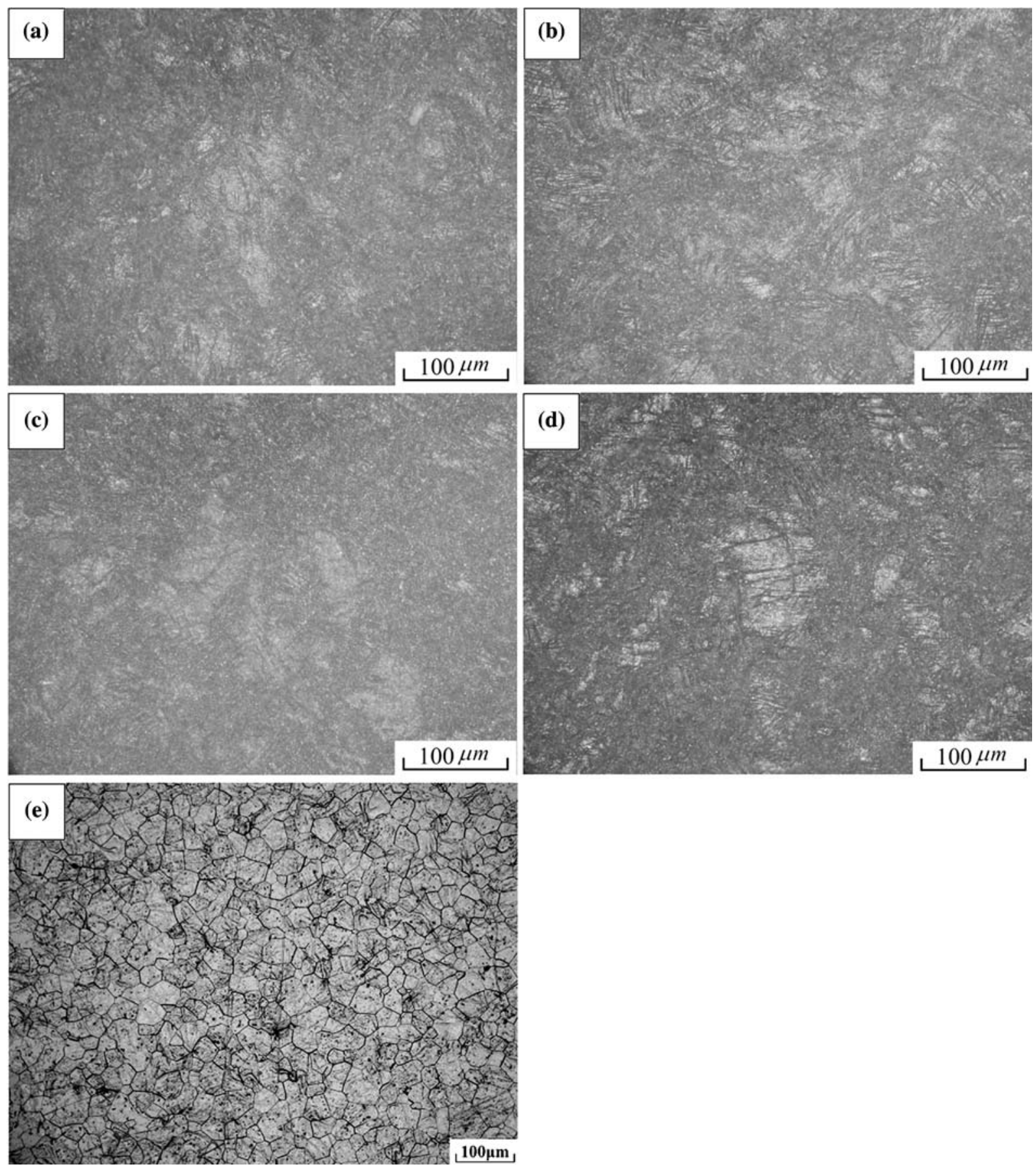

Fig. 7-Initial microstructures of undeformed specimens heated to temperatures of $(a) 25^{\circ} \mathrm{C},(b) 300{ }^{\circ} \mathrm{C},(c) 500{ }^{\circ} \mathrm{C},(d) 700{ }^{\circ} \mathrm{C}$, and $(e) 900{ }^{\circ} \mathrm{C}$.

both twins and twin interactions in $\alpha$-phase titanium alloy deformed at a high strain rate of $3 \times 10^{3} \mathrm{~s}^{-1}$, no evidence of twinning was found in the current biomedical Ti alloy in the high-strain-rate tests performed at room temperature.

However, Figures 8(c) and (d) suggest that the presence of $\alpha$ phase in the matrix also contributes to the strengthening effect observed in the deformed alloy at temperatures lower than $700{ }^{\circ} \mathrm{C}$. Specifically, the $\alpha$ phase presents a barrier to dislocation movements, causing the dislocations to pile up at the phase boundary. It seems reasonable to assume that the amount of precipitated $\alpha$ phase has a direct effect on the mechanical behavior of the Ti alloy. ${ }^{[35,36]}$ As the deformation temperature is increased, the thermal energy of the dislocations is also increased, and, hence, their ability to overcome short-range barriers is enhanced. Therefore, at a strain rate of $8 \times 10^{2} \mathrm{~s}^{-1}$ and a temperature of $300{ }^{\circ} \mathrm{C}$, the dislocation cells have a looser structure and the dislocation density is reduced. Furthermore, a greater amount of $\alpha$ phase is precipitated (Figure $8(\mathrm{e})$ ). However, for the same deformation 


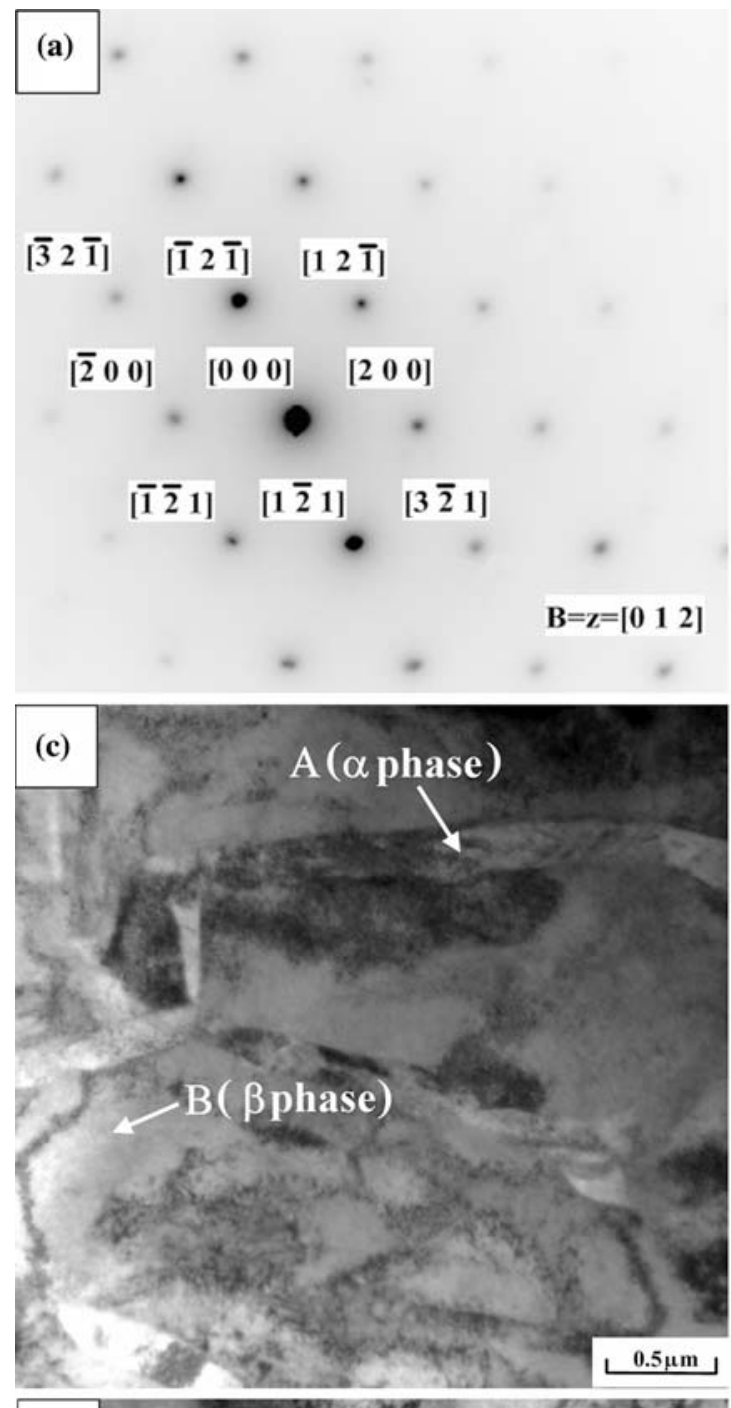

(b)

\section{$\left[\begin{array}{lll}0 & \overline{1} & 1\end{array}\right]$}
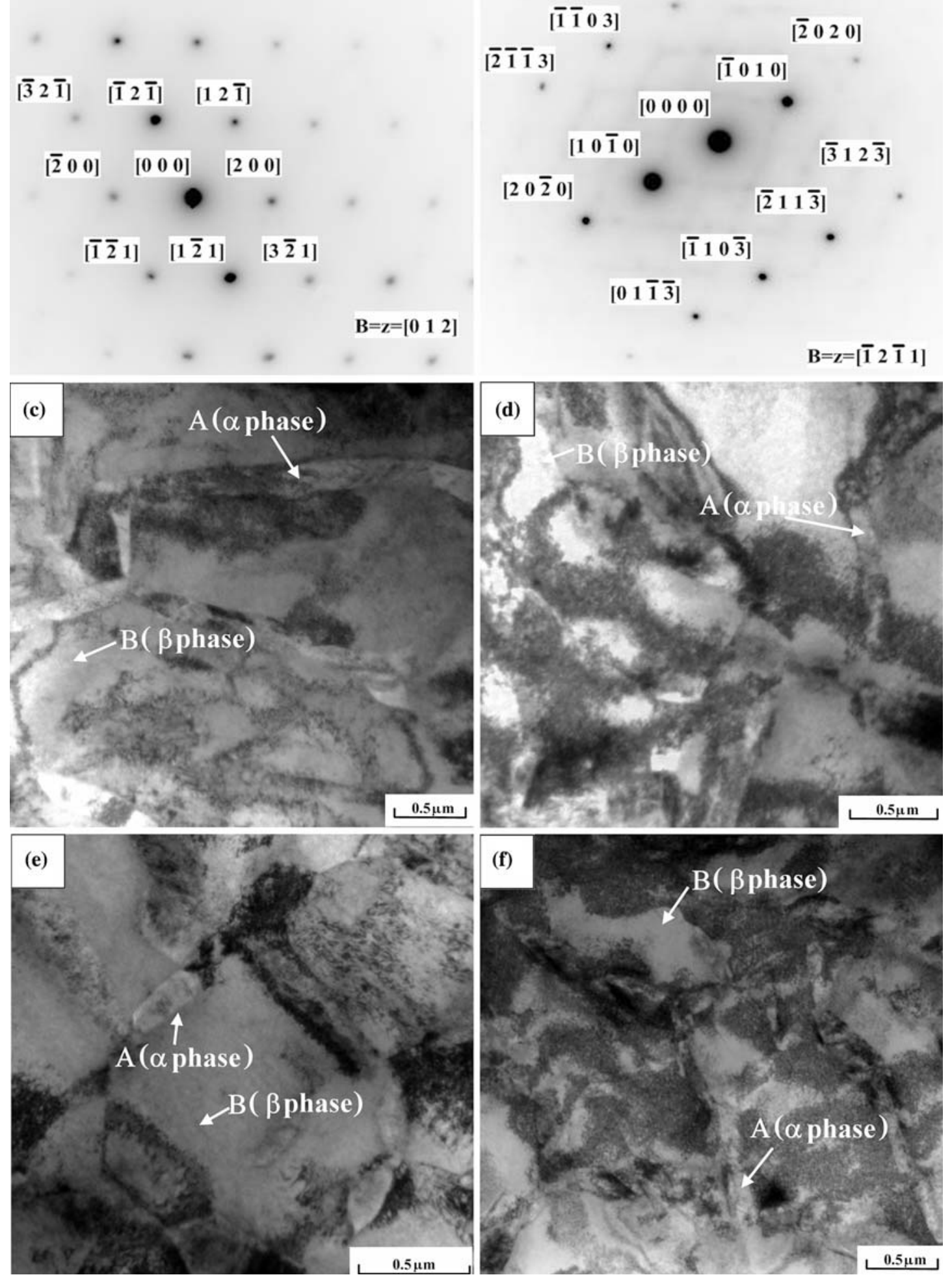

Fig. 8- (a) Diffraction pattern of $\beta$ matrix and $(b)$ diffraction pattern of $\alpha$ phase. Dislocation substructure and $\alpha$-phase precipitation in specimens deformed at true strain of 0.2 and loading conditions of $(c) 25^{\circ} \mathrm{C}, 8 \times 10^{2} \mathrm{~s}^{-1}$, (d) $25{ }^{\circ} \mathrm{C}, 8 \times 10^{3} \mathrm{~s}^{-1}$, (e) $300{ }^{\circ} \mathrm{C}, 8 \times 10^{2} \mathrm{~s}^{-1}$, and $(f)$ $300{ }^{\circ} \mathrm{C}, 8 \times 10^{3} \mathrm{~s}^{-1}$.

temperature, but at an increased strain rate of $8 \times 10^{3}$ $\mathrm{s}^{-1}$, both the dislocation density and the cell-wall thickness are increased (Figure 8(f)).
At higher temperatures of $500{ }^{\circ} \mathrm{C}$ and $700{ }^{\circ} \mathrm{C}$, the number of dislocations decreases. As a result, at a strain rate of $8 \times 10^{2} \mathrm{~s}^{-1}$, the dislocation density is lower than 
that observed at $25{ }^{\circ} \mathrm{C}$ or $300{ }^{\circ} \mathrm{C}$ under the same strain rate, as shown in Figures 9(a) and (c), respectively. Fewer dislocations and no cell substructures are found in the specimens tested at $500{ }^{\circ} \mathrm{C}$ and $700{ }^{\circ} \mathrm{C}$, respectively, because the higher temperature accelerates the annihilation of the dislocation substructures. However, at equivalent temperatures, but at a higher strain rate of $8 \times 10^{3} \mathrm{~s}^{-1}$, the dislocation-multiplication phenomenon is not significantly restrained by the higher temperature conditions. As a result, large dislocations and cell structures are still formed at temperatures of $500{ }^{\circ} \mathrm{C}$ and $700{ }^{\circ} \mathrm{C}$, as shown in Figures 9(b) and (d), respectively. Comparing the cell substructures formed at a strain rate of $8 \times 10^{3} \mathrm{~s}^{-1}$ in Figures $8(\mathrm{~d})$ and (f) and 9(b) and (d), it is apparent that the cell size increases and the cell walls become thinner as the temperature is increased. Furthermore, in comparing Figures 8(e), 9 (a), and 9 (c) at a strain rate of $8 \times 10^{2} \mathrm{~s}^{-1}$, it is observed that the amount of $\alpha$ phase precipitated in the $\beta$ matrix at $500{ }^{\circ} \mathrm{C}$ and $700{ }^{\circ} \mathrm{C}$ is greater than that formed at $300{ }^{\circ} \mathrm{C}$. The increased amount of $\alpha$ phase increases the resistance to dislocation movements and causes a greater accumulation of tangled dislocations at the $\alpha$-phase boundary. Accordingly, plastic deformation is suppressed, and the mechanical strength of the alloy is increased. As shown previously in Figure 6(a), an obvious resistance to thermal softening occurs at a temperature of $700{ }^{\circ} \mathrm{C}$. It is thought that the presence of $\alpha$ phase in the matrix dominates the high-temperature strength characteristics of Ti alloy at temperatures lower than the $\beta$-transus temperature, i.e., $785{ }^{\circ} \mathrm{C} .{ }^{[37]} \mathrm{How}-$ ever, at higher temperatures, i.e., $900{ }^{\circ} \mathrm{C}$, the microstructures of the specimens deformed at strain rates of $8 \times 10^{2} \mathrm{~s}^{-1}$ and $8 \times 10^{3} \mathrm{~s}^{-1}$ contain subgrains and a very low number of dislocations (Figures 9(e) and (f), respectively). Furthermore, since the temperature is higher than the $\beta$-transus temperature, the $\beta$ matrix contains no $\alpha$ phase. The combined effects of thermal activation assistance at higher deformation temperatures and the absence of $\alpha$ phase reduce the intensity of the driving force required to produce dislocation movements, and, hence, the flow stress reduces considerably at temperatures ranging from $700{ }^{\circ} \mathrm{C}$ to $900{ }^{\circ} \mathrm{C}$, as evidenced in Figure 2.

\section{E. Quantitative Analysis of Dislocation Density and $\alpha$ Phase}

The correlation between the microstructural evolution of the Ti alloy and its macromechanical response can be quantified by measuring the dislocation density and the amount of $\alpha$ phase within the matrix. In this study, the dislocation density, $\rho$, was determined using the analytical formula proposed by Ham, ${ }^{[38]}$ i.e., $\rho=2 n / L t$, where $n$ is the number of intersections between a dislocation and a random set of lines of length, $L$, and $t$ is the foil thickness. In performing the analysis, the dislocation density was calculated for the specimens deformed at a strain of 0.2 under each of the current strain-rate/temperature conditions. Figure 10 reveals that the square root of the dislocation density increases linearly with the flow stress, which implies that the combined effect of the strain rate and the temperature determines the correlation between the dislocation density and the flow stress. Quantitative measurements of the amount of $\alpha$ phase precipitated in the $\beta$ matrix were obtained via X-ray diffraction. Figure 11 presents the X-ray diffraction profiles of the Ti alloy deformed at temperatures ranging from $25^{\circ} \mathrm{C}$ to $900{ }^{\circ} \mathrm{C}$ at a constant strain rate of $8 \times 10^{2} \mathrm{~s}^{-1}$. It can be seen that peaks corresponding to $\alpha$ phase $(10 \overline{1} 1)$ are present only in the profiles corresponding to temperatures of $700{ }^{\circ} \mathrm{C}$ or lower and are particularly strong at temperatures of $500{ }^{\circ} \mathrm{C}$ and $700{ }^{\circ} \mathrm{C}$. The amount of $\alpha$ phase in the $\beta$ matrix was estimated quantitatively by computing the $\alpha$ phase intensity, $I_{\alpha}$, in accordance with the following equation: ${ }^{[39]}$

$$
I_{\alpha}=I\{10 \overline{1} 1\}_{\alpha} / I\{200\}_{\beta}
$$

where $I\{200\}_{\beta}$ is the base reflection intensity, i.e., the intensity of the pure $\beta$ matrix.

Figure 12 plots the variations of the dislocation density, the $\alpha$-phase intensity, and the flow stress with the deformation temperature as a function of the strain rate at a true strain of 0.2 . The results show that for a given strain rate, the flow stress and the dislocation density decrease as the temperature increases. It is also observed that the intensity of the $\alpha$ phase increases with increasing temperature below the $\beta$-transus temperature. The precipitated $\alpha$ phase not only imposes barriers to dislocation motion but also acts as the origin of dislocation multiplications. Therefore, an increased amount of $\alpha$ phase induces the generation of additional dislocations and leads to an obvious softening resistance effect (particularly at a temperature of $700{ }^{\circ} \mathrm{C}$ ).

Figure 12 confirms that the presence of $\alpha$ phase in the $\beta$ matrix results in a strengthening effect in the current $\mathrm{Ti}$ alloy at temperatures lower than $700^{\circ} \mathrm{C}$. However, Figure 13 shows that the fracture strain decreases with an increasing amount of $\alpha$ phase at temperatures lower than $700{ }^{\circ} \mathrm{C}$. The microstructural observations presented in Figures 8 and 9 reveal that the formation of $\alpha$ phase causes the accumulation of dislocations at the phase boundaries, resulting in extreme stress concentrations. Thus, cracks form more readily within the microstructure, and, hence, the fracture strain reduces. However, at temperatures higher than the $\beta$-transus temperature, $\alpha$ phase is not precipitated in the matrix, and, hence, the fracture strain increases.

\section{F. Localized Adiabatic Shearing}

Fractographic analysis reveals that the current specimens fracture as a consequence of adiabatic-shear band formation. The fracture states presented in the righthand column of Table 1 show that the formation of adiabatic-shear bands is strongly dependent on both the strain rate and the temperature. At the lowest temperature of $25^{\circ} \mathrm{C}$, all three specimens fracture as a result of adiabatic shearing. However, at temperatures between $300{ }^{\circ} \mathrm{C}$ and $700{ }^{\circ} \mathrm{C}$, adiabatic shearing takes place only at strain rates higher than $3 \times 10^{3} \mathrm{~s}^{-1}$, while at the highest temperature of $900{ }^{\circ} \mathrm{C}$, adiabatic-shear bands 

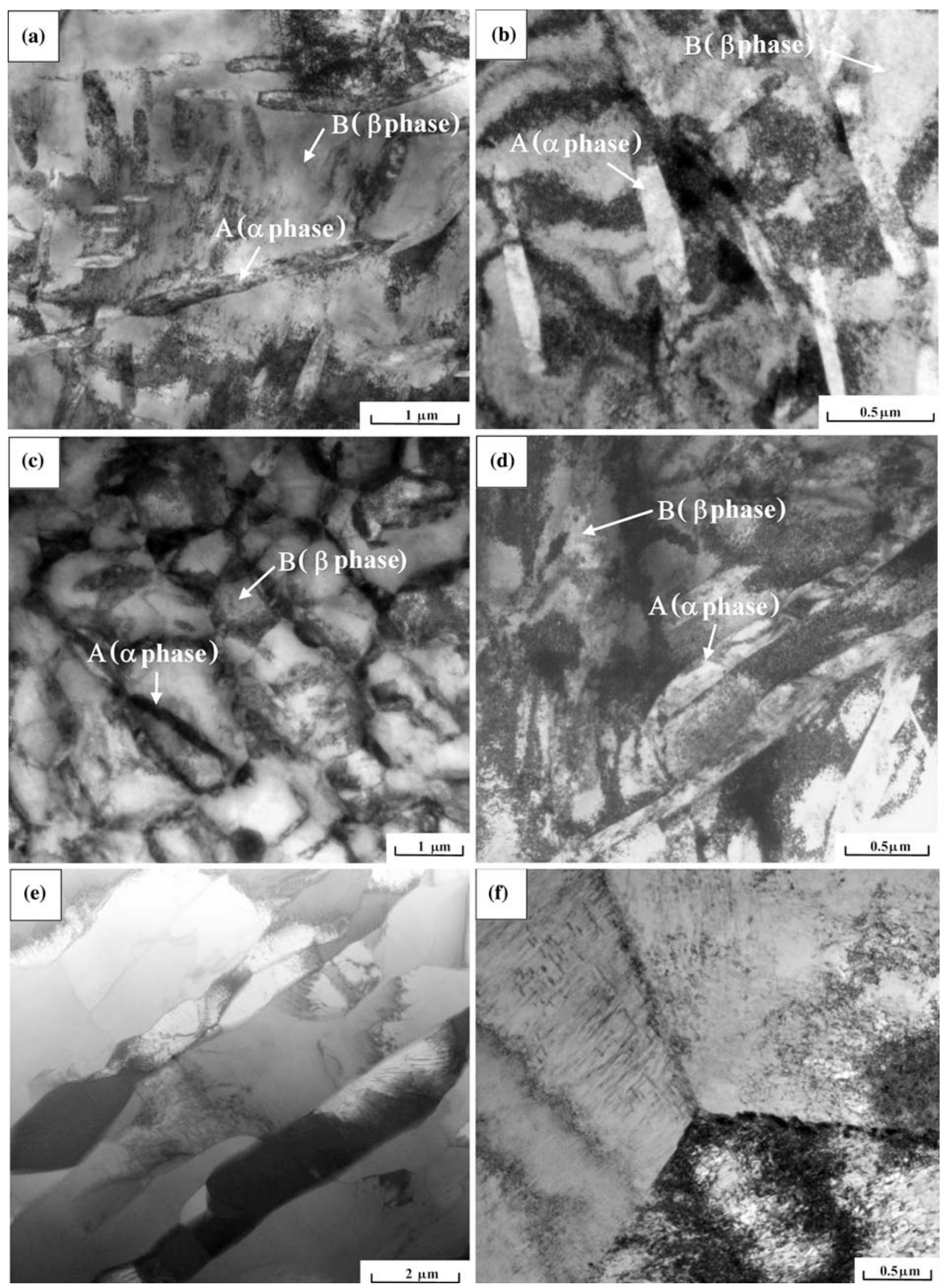

Fig. 9-Dislocation substructure and $\alpha$-phase precipitation in specimens deformed at true strain of 0.2 and loading conditions of $(a) 500{ }^{\circ} \mathrm{C}$, $8 \times 10^{2} \mathrm{~s}^{-1}$; (b) $500{ }^{\circ} \mathrm{C}, 8 \times 10^{3} \mathrm{~s}^{-1},(c) 700^{\circ} \mathrm{C}, 8 \times 10^{2} \mathrm{~s}^{-1}$, (d) $700{ }^{\circ} \mathrm{C}, 8 \times 10^{3} \mathrm{~s}^{-1},(e) 900{ }^{\circ} \mathrm{C}, 8 \times 10^{2} \mathrm{~s}^{-1}$, and $(f) 900{ }^{\circ} \mathrm{C}, 8 \times 10^{3} \mathrm{~s}^{-1}$. 


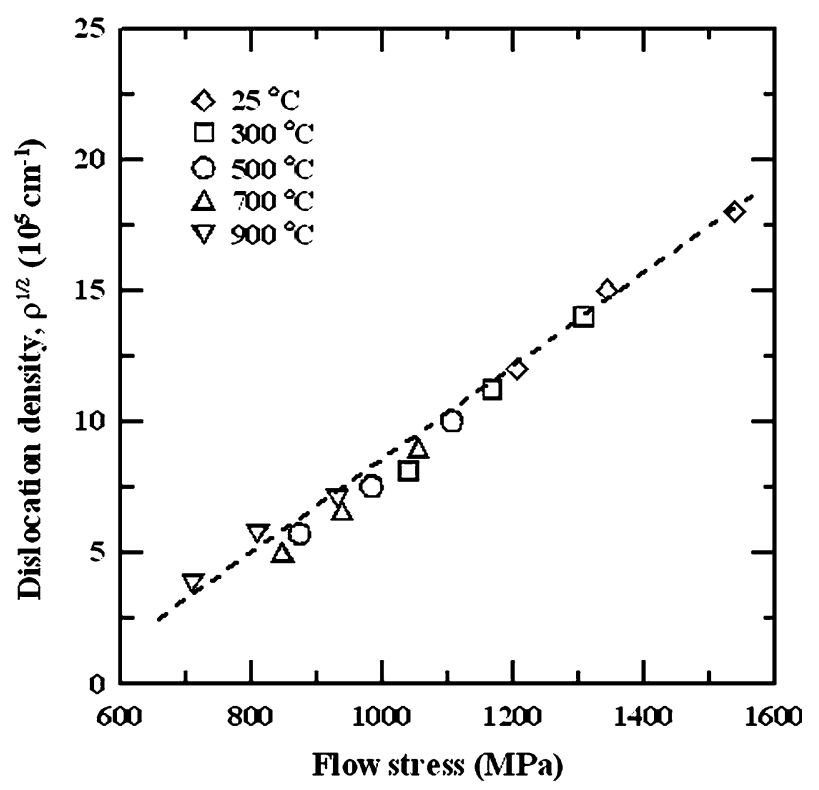

Fig. 10-Variation of square root of dislocation density as function of flow stress.

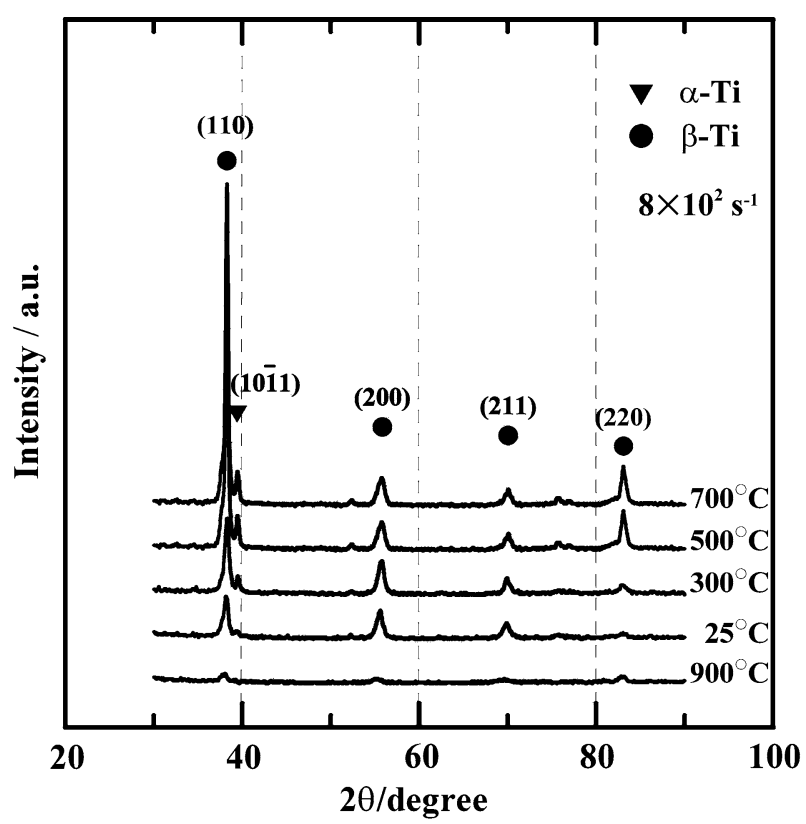

Fig. 11-X-ray diffraction profiles of Ti alloy deformed at $8 \times 10^{3} \mathrm{~s}^{-1}$ and temperatures ranging from $25^{\circ} \mathrm{C}$ to $900{ }^{\circ} \mathrm{C}$.

are formed only at the highest strain rate of $8 \times 10^{3} \mathrm{~s}^{-1}$. Overall, the results indicate that the tendency toward adiabatic shearing increases with increasing strain rate and reducing temperature.

Figure 14(a) presents a low-magnification micrograph of a specimen tested at a temperature of $25^{\circ} \mathrm{C}$ and a strain rate of $8 \times 10^{3} \mathrm{~s}^{-1}$. It can be seen that the specimen fails in a catastrophic manner along a plane

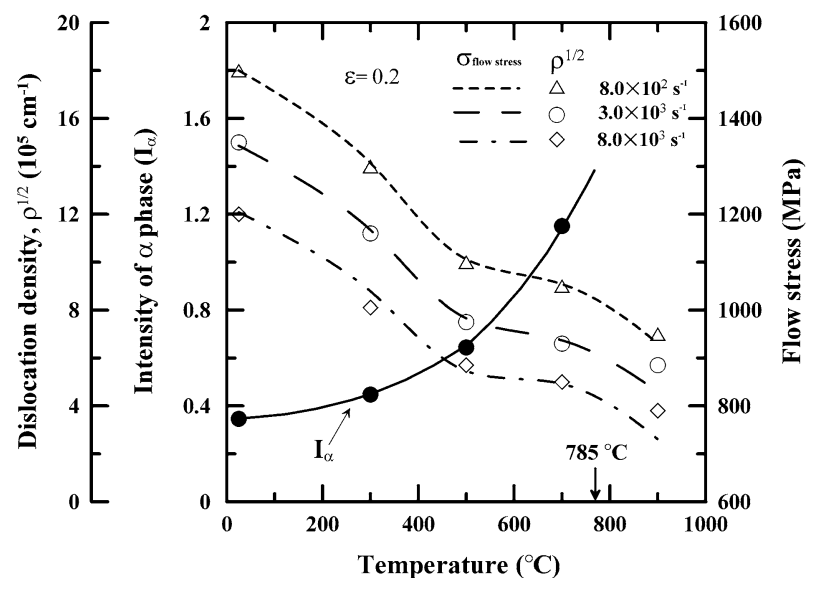

Fig. 12-Variation of dislocation density, $\alpha$-phase intensity, and flow stress with temperature as function of strain rate.

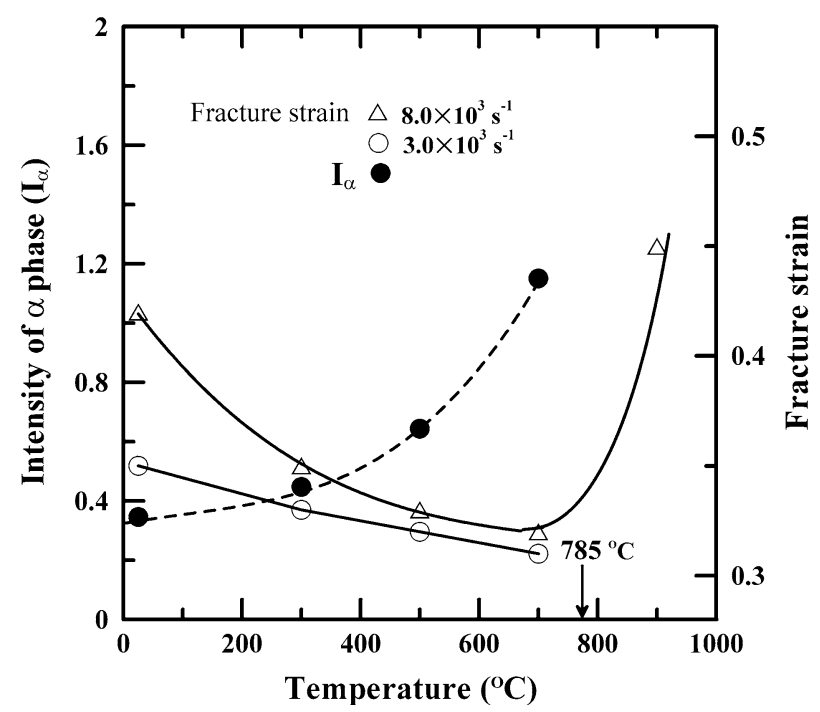

Fig. 13-Variation of $\alpha$-phase intensity and fracture strain with temperature as function of strain rate.

orientated at an angle of 40 to 50 deg to the compression axis. Figure 14(b) shows the fragmentation features of the failed specimen. Figures 14(c) and (d) present optical micrographs of the transverse sections (i.e., perpendicular to the compression axis) of sheared specimens deformed at a strain rate of $8 \times 10^{3} \mathrm{~s}^{-1}$ under temperatures of $25^{\circ} \mathrm{C}$ and $900{ }^{\circ} \mathrm{C}$, respectively. The micrographs show that adiabatic-shear bands propagate along a circular path on the transverse section of each specimen. Interestingly, double localized shear bands are formed in the specimen tested at a strain rate of $8 \times 10^{3} \mathrm{~s}^{-1}$ and a temperature of $900{ }^{\circ} \mathrm{C}$, as shown in Figure 14(d). The formation of this double shear band can be attributed to the change in the deformed microstructure from a mixed $\alpha+\beta$ phase at temperatures lower than the $\beta$-transus temperature to a single $\beta$ phase at higher temperatures. 

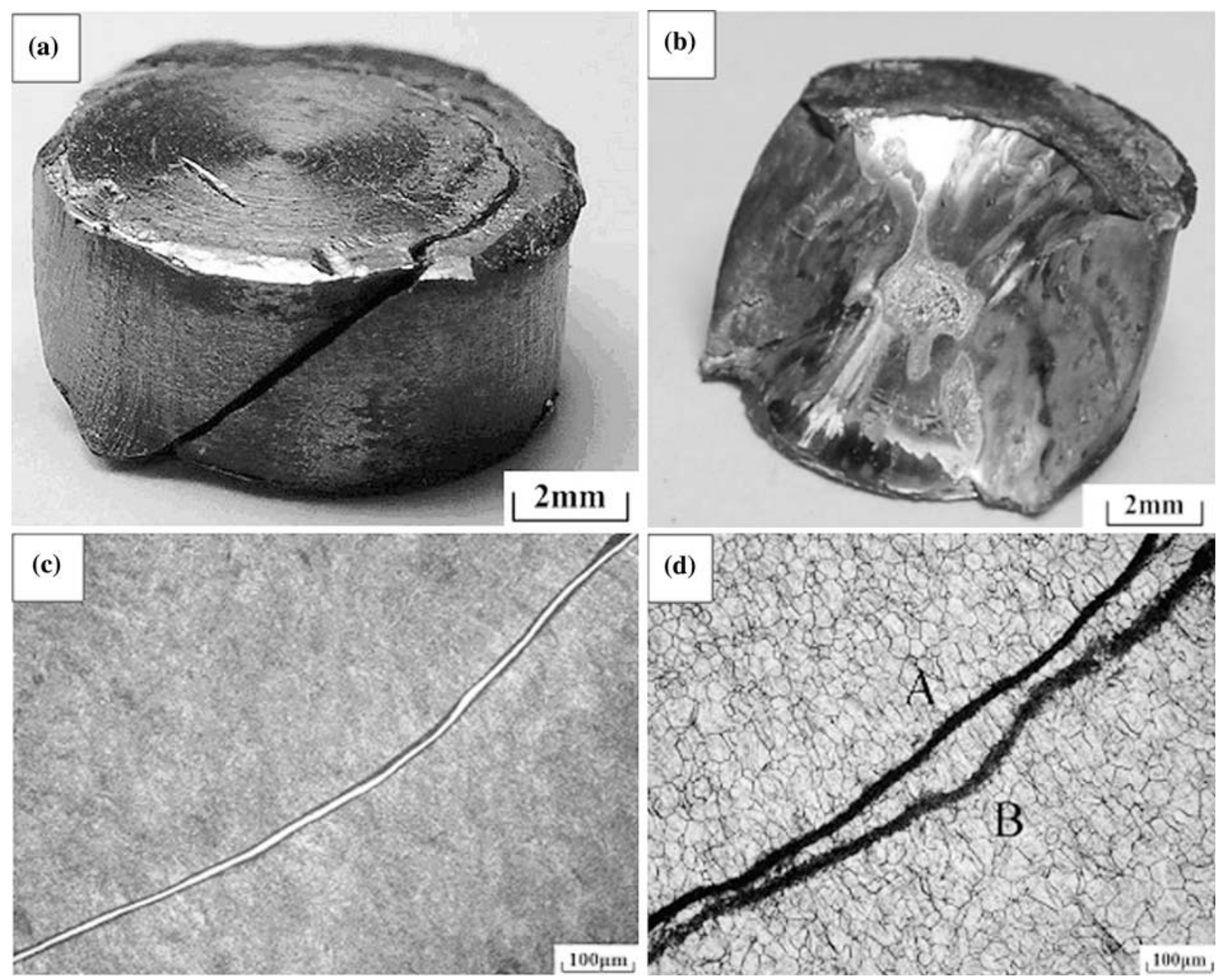

Fig. 14 - (a) Low-magnification SEM fractograph of specimen deformed at $8 \times 10^{3} \mathrm{~s}^{-1}$ and $25^{\circ} \mathrm{C}$; (b) fragmentation features of failed specimen shown in (a); optical micrographs of adiabatic-shear bands in specimens deformed at (c) $8 \times 10^{3} \mathrm{~s}^{-1}, 25^{\circ} \mathrm{C}$ and $(d) 8 \times 10^{3} \mathrm{~s}^{-1}, 900{ }^{\circ} \mathrm{C}$.

\section{CONCLUSIONS}

This study has investigated the effects of strain rate and temperature on the dynamic mechanical response and microstructural evolution of Ti alloy. In general, the results have shown that the flow stress increases with increasing strain rate but decreases with increasing temperature. The competing effects of strain hardening, strain-rate hardening, and thermal softening result in a work-hardening response at low values of true strain and a work- softening response at higher values of true strain. For a given temperature, the fracture strain and work-hardening rate increase with increasing strain rate. However, for a constant strain rate, the fracture strain and work-hardening rate reduce with increasing temperature at temperatures lower than $700{ }^{\circ} \mathrm{C}$ but increase significantly at a deformation temperature of $900{ }^{\circ} \mathrm{C}$. The Ti alloy exhibits high-strain-rate sensitivity at large strains and strain rates, and at low deformation temperatures. Furthermore, an inverse relationship is found between the activation energy and the flow stress. The microstructural observations have shown that the dislocation density and the amount of precipitated $\alpha$ phase have a significant effect on the dynamic plastic deformation of the $\mathrm{Ti}$ alloy. Dislocation generation is enhanced at higher strain rates but is suppressed at higher deformation temperatures. Furthermore, the square root of the dislocation density increases linearly with an increasing flow stress. The amount of precipitated $\alpha$ phase is insensitive to the strain rate but increases with increasing temperature at temperatures lower than the $\beta$-transus temperature. The presence of $\alpha$ phase provides a strengthening effect since it assists in the generation of dislocations and suppresses their movement. However, significant stress concentrations are formed at the boundaries of the $\alpha$ phase, which result in the formation of cracks within the matrix. Hence, the fracture strain reduces as the amount of $\alpha$ phase increases.

\section{ACKNOWLEDGMENTS}

The authors gratefully acknowledge the financial support provided to this study by the National Science 
Council (NSC) of Taiwan under Contract No. NSC-93-2212-E006-076. Particular appreciation is also extended to Kobe Steel Ltd., Japan, for their supply of the Ti- alloy bars used in the current high-strain-rate deformation tests.

\section{OPEN ACCESS}

This article is distributed under the terms of the Creative Commons Attribution Noncommercial License which permits any noncommercial use, distribution, and reproduction in any medium, provided the original author(s) and source are credited.

\section{REFERENCES}

1. S.G. Steinemann: Ti Sci. Technol., 1984, vol. 2, pp. 1327-34.

2. H.S. Dobbs and J.T. Scales: Annual book of ASTM Standard, ASTM, Philadelphia, PA, 1983, pp. 173-86.

3. K.G. Nichols and D.A. Puleo: J. Biomed. Mater. Res., 1997, vol. 35 , pp. 256-71.

4. M. Katsuhiko, D. Kenji, M. Tomiharu, and S. Yoshio: Mater. Trans., 2002, vol. 43, pp. 2936-42.

5. H.M. Kim, H. Takadama, T. Kokubo, S. Nishiguchi, and T. Nakamura: Biomaterials, 2000, vol. 21, pp. 353-58.

6. B.M. Butcher and C.H. Karnes: J. Appl. Phys., 1964, vol. 37 pp. 402-11

7. F.E. Hauser: Exp. Mech., 1966, vol. 6, pp. 395-402.

8. M. Meyers, Y.J. Chen, F.D.S. Marquis, and D.S. Kim: Metall. Mater. Trans. A, 1995, vol. 26, pp. 2493-501.

9. A.M. Bragov and A.K. Lomunov: Int. J. Impact Eng., 1995 , vol. 16, pp. 321-30.

10. W.S. Lee and C.F. Lin: Metall. Mater. Trans. A, 2002, vol. 33A, pp. 2801-10.

11. L.E. Murr: Scripta Metall., 1978, vol. 12, pp. 201-06.

12. W.S. Lee, J.C. Shyu, and S.T. Chiou: Scripta Mater., 2000, vol. 42 , pp. $51-56$.

13. R. Boyer, G. Welsch, and E.W. Collings: Materials Properties Handbook: Titanium Alloys, ASM, Materials Park, OH, 1994, pp. $949-56$
14. M. Ikeda, S.Y. Komatsu, T. Sugimoto, and M. Hasegawa: Mater. Sci. Eng. A, 1998, vol. 243, pp. 140-45.

15. S.Y. Komatsu, M. Ikeda, T. Sugimoto, K. Kamei, O. Maesaki, and M.A. Kojima: Mater. Sci. Eng. A, 1996, vol. 213, pp. 61-65.

16. O.M. Ivasishin, P.E. Markovsky, S.L. Semiatin, and C.H. Ward: Mater. Sci. Eng. A, 2005, vol. 405, pp. 296-305.

17. U.S. Lindholm: J. Mech. Phys. Sol., 1964, vol. 12, pp. 317-35.

18. J.L. Chiddister and L.E. Malvern: Exp. Mech., 1963, vol. 3, pp. 81-90.

19. W.S. Lee and C.F. Lin: Mater. Sci. Eng. A, 1998, vol. 241, pp. 48-59.

20. D.R. Chichili, K.T. Ramesh, and K.J. Hemker: Acta Mater., 1998, vol. 46 (3), pp. 1025-43.

21. K.T. Ramesh: Metall. Mater. Trans. A, 2002, vol. 33, pp. 927-35.

22. A.S. Khan, Y.S. Suh, and R. Kazmi: Int. J. Plast., 2004, vol. 20, pp. 2233-48.

23. G. Regazzoni, U.F. Kocks, and P.S. Follansbee: Acta Metall., 1987, vol. 35, pp. 2865-75.

24. P.S. Follansbee and U.F. Kocks: Acta Metall., 1988, vol. 36, pp. 81-93.

25. W.S. Lee and C.F. Lin: Metall. Mater. Trans. A, 2002, vol. 33, pp. 2801-10

26. F.J. Zerilli and R.W. Armstrong: Acta Metall. Mater., 1992, vol. 40, pp. 1803-08.

27. S.S. Egg, Y.Q. Sue, and P.B. Hirsch: Mater. Sci. Eng. A, 1995, vols. 192-193, pp. 45-52.

28. G. Regazzoni, U.F. Kocks, and P.S. Follansbee: Acta Metall., 1987, vol. 35, pp. 2865-75.

29. H. Conrad and H. Wiedersich: Acta Metall., 1960, vol. 8, pp. 128-30.

30. L. Shi and D. O. Northwood: Acta Metall. Mater., 1995, vol. 43, pp. $453-60$

31. A. Gilat and X. Wu: Int. J. Plast., 1997, vol. 13, pp. 611-32.

32. A.J. Boehlert: Mater. Sci. Eng. A, 1989, vol. 267, pp. 82-98.

33. A.A. Morrone: Ph.D. Dissertation, Brown University, Providence, RI, 1986, p. 34.

34. W.S. Lee and C.Y. Liu: Metall. Mater. Trans. A, 2005, vol. 36A, pp. $3175-86$.

35. S.Y. Komatsu, M. Ikeda, T. Sugimoto, K. Kamei, O. Maesaki, and M.A. Kojima: Mater. Sci. Eng. A, 1996, vol. 213, pp. 61-65.

36. G.H. Narayanan and T.F. Archbold: Metall. Trans., 1970, vol. 1, pp. 2281-90.

37. G.G. Yapici, I. Karaman, Z.P. Luo, and H. Rack: Scripta Mater., 2003, vol. 49, pp. 1021-27.

38. R.K. Ham: Philos. Mag., 1961, vol. 6, pp. 1183-84.

39. T. Nishimura, M. Nishigaki, and Y. Moriguchi: R\&D Technical Report, Kobe Steel, Chuo-Ku, Kobe, Japan, 1982, vol. 32, pp. $52-55$ 